\title{
Vasari: la idea de Renacimiento en Le Vite
}

\begin{abstract}
C IORGIO Vasari (1511-1574), fusión de artista y literato, fue un 0 apologista del Renacimiento, y si bien no alcanzó la excelsitud en ninguna de las artes - la crítica moderna está de acuerdo en reconocer que su mayor grandeza como artista se encuentra en la arquitectura-, en cambio, gracias a su espíritu entusiasta, fue como una esponja que se empapó en el rico espíritu de su tiempo. Con gran sensibilidad absorbió las ideas que flotaban en su ambiente; amigo de Papas, cardenales, príncipes, literatos y artistas, supo aprovechar la familiaridad que mantuvo con ellos para légarnos una de las obras más vastas y grandes de todos los tiempos: Vite de' piú eccellenti pittori, scultori e architetti, cuya primera edición apareció en 1550, impresa por Lorenzo Torrentino, impresor ducal, dedicada a Cosimo de Medici.

Su vida se desarrolló en el periodo tardio del Renacimiento, cuando los mayores artistas habían alcanzado la cumbre de su arte, y en aquel tiempo dificil para Italia bajo las presiones extranjeras y las tiranías de los príncipes, en el que muchos de los grandes ideales fueron cuestionados. Vasari intuyó los grandes ideales políticos y artísticos, sus conflictos, sus aspiraciones y contradicciones; a su manera se percató de la decadencia y dirigió su mirada más al pasado reciente que al presente o al futuro. No obstante su rica sensibilidad, su capacidad de asimilación y su espíritu emprendedor, no fue un innovador sino un crítico-artista que a través de su ánimo entusiasta de biógrafo y narrador, explicitó sus opiniones y exaltó todo lo que en el arte había concluido o estaba por concluir. Con agudo sentido de la belleza destacó una notable capacidad por construir y organizar todo lo que ese vasto mundo en estudio y experiencias habia suscitado en él. Su mundo más rico fue naturalmente el del arte, aquél al que tanto tiempo de su vida dedicó; a través de este mundo propio reflejó el mundo del arte de su tiempo, en un momento en el que el arte había
\end{abstract}


alcanzado su autonomía y las obras de arte eran expresión de la personalidad del artista que las creaba.

La aparición de Le Vite no fue por tanto accidental. Fue posible sólo cuando los conceptos básicos del medioevo fueron rechazados para dar paso a una historiografia artística fundada sobre un nuevo concepto del arte. La descripción de obras de arte con carácter meramente topográfico o las guías sobre monumentos y obras artísticas de las ciudades continuaron, pero el interés por la individualidad humana y la elevación de las artes plásticas al rango de las artes liberales, proporcionó al Renacimiento los elementos necesarios para una historiografia artística en toda la extensión del término. Le Vite fue durante siglos modelo de la historiografia artística de Europa.

Vasari formuló su hipótesis extrapolando su experiencia y sus lecturas en materia artística y con base en esa hipótesis intentó explicar el desarrollo de las artes. Su idea inicial fue desencadenar una explicación con base en una información que le mostraba el gradual perfeccionamiento de las artes. Su ingenio y capacidad le permitieron descubrir la existencia de posibles analogías entre las realidades artístico-históricas que analizaba.

Pero estas ideas no son del todo nuevas. El Renacimiento veía su cultura como un gran progreso en todos los dominios, en comparación con la Edad Media. Mondolfo señala cómo "la idea de progreso humano, que tiene sus antecedentes y sus primeras manifestaciones en el pensamiento griego, se afirmó como solución histórica del conflicto entre antigüedad y modernidad en la época del Renacimiento"'. Esta tendencia se manifestó en Vasari en el momento en que se vio obligado a establecer una confrontación entre dos épocas y cuando trató de rechazar las pervivencias de la anterior.

La idea de continuidad en el desarrollo artístico se había manejado con anterioridad a Vasari, pero el mérito del autor de $L e$ Vite fue el haberla reconocido en toda su significación. Esta idea del desarrollo, dice Kallab, no es el resultado de su obra sino su condición; gracias a ella pudo manejar su cuantioso material con seguridad y ligereza. Sin esta condición le habría sido difícil llevar a cabo tan grande empresa. Otra ventaja que le confería esta seguridad fue que su obra estaba muy unida a su práctica artística. ${ }^{2}$

Vasari escribe:

1 Mondolfo, Rodolfo, Tres filósofos del Renacimiento, Bruno, Galileo, Campanella, Buenos Aires, Losada, 1974, p. 175.

2 Kallab, W., Vasaristudien, vol. 15, Quellenschriften für Kunstgeschichte und Kunsttechnik des Mittelalters, Víena und Leipzig, 1908, p. 408. 
Señalaré mis intenciones y mostraré con qué fin he dividido Le Vite en tres partes... Como en ella he hablado suficiente de los modos, de las maneras y de las causas del bueno, del mejor y del óptimo operar de los artífices, hablaré ahora en general, considerando las características de los tiempos más que las características de las personas. Para no analizar demasiado minuciosamente, he dividido la obra en tres partes o edades, desde el Renacimiento de estas artes hasta el siglo que vivimos, por aquellas sus manifiestas diferencias que en cada caso se conocen...

...En la primera y más antigua se ha visto que estas tres artes están lejos de la perfección y aunque poseen alguna cosa de bueno, al ser acompañadas de tantas imperfecciones no merecen gran alabanza, aunque por haber indicado el camino, el principio y el modo a lo que siguió después debemos darles un poco de gloria. Pero si se juzgaran de acuerdo con la regla perfecta del arte, no la merecerian por sí mismas...

...En la segunda se ve manifiestamente que las cosas han mejorado tanto en inventiva como en la ejecución, con mejor dibujo y manera y con mayor diligencia, y así desaparecen aquellas asperezas de la antigüedad y aquella desproporción que la tosquedad de aquel tiempo había dado...

...Pero, ¿quién se atreverá a decir que en aquel tiempo fuera posible encontrar cosas tan perfectas que reuniesen la perfección de hoy ên cuanto a invención, dibujo y colorido?... Esta alabanza ciertamente corresponde a la tercera edad, en la cual me parece poder decir seguramente que el arte ha llegado a tal imitación de la naturaleza y alcanzado un grado tan alto, que muy pronto se pueda temer una caida más que esperar en adelante una superación...

\section{Vasari, meditando atentamente sobre estas artes, agrega:}

Considero que una propiedad y una particularidad̀ natural de estas artes es que de un humilde principio van poco a poco mejorando y llegan finalmente a la cima o cumbre de su perfección. Y esto me lo hace creer el observar... que lo mismo se repite en todas las artes libe. rales. ${ }^{4}$

Sobre la base de estas ideas, Vasari se propuso reconstruir la historia continuada de los artífices "desde Cimabue hasta nuestros días". Partió de lo que él llamó rinascita. Este despertar, dispuesto en tres etapas, comienza hacia mediados del siglo XII y se prolonga hasta

${ }^{3}$ Vasari, Giorgio, Vite de' piú eccellenti pittori, scultori e architetti, Siena, Pazzini Carli e Co., 1791-94, 11 vols. Proemio alla seconda parte, III, 2-3.

${ }^{4}$ Ibid., Proemio alla seconda parte, III, 4 
La base para la evolución del arte es para Vasari el naturalismo, es decir, la imitación de la naturaleza, imitación que en los primeros decenios del Cinquecento había alcanzado, a través de la seguridad del dibujo, "la perfecta maniera". Después, pese a los elogios que prodiga, siente que el arte italiano decae. Sólo en la segunda edición de 1568 se podría delinear una "cuarta edad", que es la de sus contemporáneos. Al lado del criterio naturalista aparecen en la mente de Vasari otros principios: la necesidad de la riqueza de las invenciones; el dominio del desnudo según el concepto antiguo; la exigencia de la facilidad manual y otros más. Estos principios fueron muy difundidos durante el manierismo, fenómeno artístico del que Vasari llegó a tener una conciencia muy clara, pese a que esta etapa de historicidad artística, inscrita en pleno Renacimiento, no haya sido detectada por historiadores y estudiosos sino hasta principios del presente siglo. A los actuales conceptos sobre manierismo mucho debe la relectura y revaloración de Le Vite.

\section{Su idea de Renacimiento}

Johan Huizinga, en su ensayo "El problema del Renacimiento"'s dice que "el Renacimiento fue como Proteo. No hay concordancia en ninguno de los problemas que a él se refieren: cuándo comenzó y cuándo concluyó; si la cultura clásica fue una de sus causas o sólo un fenómeno concomitante; si es imposible separar al Renacimiento del humanismo. No hay definición del concepto de Renacimiento por lo que toca al tiempo, a la amplitud, al contenido ni al significado", por lo que "el problema de lo que el Renacimiento fue realmente no puede desprenderse del desarrollo del término que lo designa".

Originariamente se dio el nombre de Renacimiento al movimiento que en el siglo XV y principios del XVI intentó resucitar en la cultura europea los valores formales y espirituales de la antigüedad grecorromana. A través de los estudios de $\mathrm{Mi}$ chelet y de Burckhardt este movimiento fue definido con más amplitud. Michelet, en su Historia de Francia (1855), consideró el Renacimiento como el período en que un nuevo sentido de

5 Huizinga, Johan, en Hombres e Ideas, Ensayo de historia de la cultura, Buenos Aires, Compañía General Fabril Editora, 1960, p. 216. 
la personalidad individual y un nuevo conocimiento de la naturaleza del mundo permitieron la independencia y la autonomía del hombre. Esta interpretación fue reforzada por Jakob Burckhardt en La cultura del Renacimiento en Italia (1860), donde la cultura de los siglos XV y XVI fue vista como el Renacimiento del paganismo que preparó el camino para Lutero y la Reforma. Para Burckhardt los pensadores del Renacimiento fueron una especie de profetas que lucharon contra las fuerzas corruptas del Papado. Esta imagen, expandida y popularizada por Symonds y otros, fue la que predominó en la segunda mitad del siglo XIX.

El Renacimiento representó una nueva y muy importante fase en la transmisión, estudio e intepretación de la herencia clásica de la antigüedad. Bajo la influencia de los modelos clásicos, el humanismo renacentista llevó a cabo una profunda transformación en la sociedad, las artes, la literatura, las ciencias y la enseñanza clásica.

En el arte, el Renacimiento se inició con una manifestación de naturalismo, y Giotto ha sido considerado como el primer antecesor y pilar del movimiento. Los escritores del Trecento, comenzando por Dante, han destacado la gran importancia de Giotto como el artista que cambió la concepción, los modos, la finalidad del arte, ejerciendo una gran influencia sobre la cultura de su tiempo. Dante, consciente de su propia dignidad de literato, reconoció en Giotto a un igual, destacando y elevando su posición sobre los maestros que le precedieron. La idea de Dante de que los grandes maestros no pertenecen al común de la gente, haría eco. Petrarca mismo, nos dice Panofsky, ${ }^{6}$ "conmovido... por la contemplación de las ruinas de Roma, dolorosamente consciente del contraste entre un pasado de cuya magnificencia daban aún testimonio los vestigios de su arte y literatura... y un presente deplorable que lo colmaba de dolor... vio - la historia- escindida en dos periodos, el clásico y el reciente". Petrarca consideró la antigüedad clásica como una edad de "pura claridad", y la época siguiente a la conversión de Constantino, como una "edad de tenebrosa ig-

6 Panofsky, E., Renacimiento y tenacimientos en el arte occidental, Madrid, Alianza Universidad, 1975, p. 42. 
norancia", lo que equivalía a una inversión completa de los valores religiosos y culturales establecidos hasta aquel entonces. No obstante, Panofsky considera que la esperanza de Petrarca como patriota, erudito y poeta se fundaba más en una regeneración política y sobre todo en una depuración de la dicción y gramática latinas, en una restauración del griego y una vuelta a los textos clásicos antiguos, que en la idea de una renovación general que abarcara todos los ámbitos de la cultura. Petrarca aclamó también a Giotto como al reformador de la pintura después de la "edad obscura". Bocaccio, discípulo de Petrarca e intérprete de Dante, escribe: "Giotto poseía ingenio tan excelente que no hay nada de cuanto crea la naturaleza, madre y operadora de todas las cosas, en el curso del perpetuo girar de los cielos, que él no reprodujera con el estilo, pluma o pincel con tal semejanza que parecía cosa natural y no pintada, al punto de muchas veces conducir al engaño el sentido visual de los hombres, que tomaron por verdadero lo pintado. Así, él sacó de nuevo a la luz el arte que durante muchos años había yacido sepultado... puede decirse con justicia que fue una de las luminarias de la gloria florentina". " Estas palabras esbozan la idea de una renovación opuesta al mundo medieval anterior a Giotto, e implican al mismo tiempo una idea de evolución en el progreso artístico: la antigüedad es seguida por un proceso oscuro y decadente y éste, por la era moderna en que las grandes personalidades artísticas habían de llevar al arte a su más alta expresión. Más adelante veremos cómo la idea de evolución de la maniera en Vasari sigue esta alternancia: maniera antica para la antigüedad, maniera vecchia para la Edad Media y maniera moderna para el Renacimiento.

Para Filippo Villani, Cimabue "fue el primero que por su ingenio empezó a enderezar el arte anticuado de la pintura hacia la verosimilitud, que por la ignorancia de los pintores se habian extraviado y descarriado... alejándose de la realidad. Después, de él, allanado ya el camino a la innovación, Giotto... restituyó a la pintura su prístina dignidad y gran renombre". ${ }^{8}$ En su Libro dellarte, Cennino Cennini escribe: Giotto transformó el arte de pintar del griego al latín y lo hizo moder-

7 Bocaccio, Decamerón, VI, 5.

${ }^{8}$ Panofsky, E., Op. Cit., p. 48. 
no, y su arte alcanzó una perfección como ninguno otro haya jamás igualado. ${ }^{9}$ Para Cennini, antigüedad era latinidad, es decir, Roma, cuya continuidad espiritual se había mantenido a través de la Edad Media. Roma resumía las nuevas aspiraciones, y este retorno a la antigüedad iba acompañado por una rebelión contra el mundo griego -es decir, Bizancio-, que hasta entonces había dominado el arte de la pintura. Estas ideas se encuentran también en los Comentarii de Ghiberti, quien consideró "el nuevo arte" y la doctrina de Giotto como una reacción hacia la dureza de los griegos (bizantinos). Leon Battista Alberti, en su Tratado de la.pintura (Della pittura), sin mirar demasiado hacia el pasado, consideró que el arte nuevo no era precisamente el de Giotto, sino el arte florentino de su tiempo. En sus tratados de arquitectura (De re aedificatoria) y de escultura (Della statua) se encuentran referencias tanto al mundo griego como al romano, que para él representaban la antigüedad. Filarete por su parte, en su Tratado de la arquitectura en que traza una ciudad ideal llamada "Sforzinda", basada en un espíritu humanista, considera que Roma, por haber sido la capital del imperio romano, fue el sitio donde se sentaron las bases de una teoría antropomórfica de la arquitectura. Antonio Manetti, en su Vida de Brunelleschi, señala a Brunelleschi como al que revivió la arquitectura antigua, en contraste con la arquitectura de los germanos, considerando a los godos como los destructores del estilo antiguo. Al mismo tiempo opinaba que así como los humanistas habían vuelto sus ojos a la antigüedad, el arte debía buscar su lenguaje latino (Roma), lo cual significaba el retorno a la propia tradición nacional. Cristóforo Landino, en su Prefacio a la Divina Comedia de Dante, después de discurrir sobre la pintura antigua de Egipto y de Grecia, luego extinguida, vio en el redescubrimiento de los rasgos naturalistas de Cimabue el principio de un nuevo estilo, considerando a Giotto su continuador.

Estos y otros más fueron los antecedentes que permitieron a Vasari perfilar el concepto de Renacimiento.

Huizinga nos dice que "la persona que concibió claramente el acontecimiento renacentista como un hecho histórico

${ }^{9}$ Cennini, Cennino, Il libro dell'arte, Firenze, 1943. 
acaecido en un momento preciso del pasado, y que al mismo tiempo derivó la forma italiana equivalente de la palabra Renacimiento del latín renasci, aplicándola particularmente a la restauración artística y confiriéndole por lo tanto carácter de concepto de la historia del arte, fue Giorgio Vasari... La palabra rinascita se convirtió para él en designación permanente del gran acontecimiento de la reciente historia del arte". ${ }^{10}$

Cuando nos referimos a la idea de progreso vimos cómo Vasari aceptó la continuidad como idea básica en la historia. Para él "el arte había alcanzado su culminación en la antigüedad griega y romana, a la que siguió un prolongado período de decadencia iniciado en tiempos de Constantino. Los godos y los lombardos habían derribado lo que ya se estaba derrumbando por sí mismo. Durante mucho tiempo Italia sólo había conocido el tosco, lamentable y duro arte pictórico de los bizantinos"."11

Vasari, sin embargo, al hacer uso del término rinascita, escindió, de alguna manera, la historia en dos períodos, uno de los cuales, el Renacimiento, surgió después de muchos años de oscuridad. El uso de este concepto implicó en Vasari una doble reacción: 1o) contra el arte de los germanos o tedescos y 2o) contra el arte de los bizantinos.

Para designar al gótico utiliza las expresiones maniera barbara y maniera tedesca, y aunque en términos generales incluye a todas las artes plásticas, Vasari hace especial hincapié en la arquitectura con objeto de contraponerla al arte del Renacimiento. Al gótico lo describe de la siguiente manera:

Hay otros trabajos que se llaman tedescos, que difieren de los antiguos'y de los modernos en su ornamentación y en su proporción. Este orden ha sido abandonado por nuestros buenos artistas por considerarlo monstruoso, bárbaro y carente de armonía. Más que orden puede llamarse desorden y confusión a los edificios así constuidos, que en gran número han corrompido el buen gusto. Están adornados por columnas finas y retorcidas como una cintura y carecen de fuerza suficiente para sostener cualquier peso. Además tienen innumerables ornatos y

10 Huizinga, Johan, Op. Cit., p. 218.

"Ibid., p. 219. 
pequeños tabernáculos, unos puestos sobre otros, con tantas pirámides, puntas y hojas que parece imposible que puedan sostenerse; dan más bien la impresión de estar hechos de papel y no de mármol o piedra. Tienen además de lo citado, resaltos, hendiduras, repisas y caulículos en profusión tan inmensa, que restan proporción a toda la obra, y con frecuencia, por la abundancia de adornos, la parte superior de una puerta toca el techo. Este estilo fue inventado por los godos. Como las guerras destruyeron todos los edificios antiguos y desaparecieron los arquitectos, los modernos comenzaron a construir en la forma citada, haciendo los techos en ángulo agudo y llenando toda Italia con esta maldición de edificios, que por suerte, no se erigen ya. Quiera Dios librar a los pueblos de caer en el error de concebir tales edificios, que por su deformidad y por carecer en absoluto de la belleza de nuestros estilos, no son dignos de que los describamos. ${ }^{12}$

La maniera greca o vecchia maniera greca se refiere sobre todo a la pintura bizantina, a la que le reprocha el ser lineal, el representar los ojos rasgados y abultados, las manos abiertas, las figuras apoyadas sobre las puntas de los pies y el uso de colores llamativos. En la vida de Bernardino Pinturicchio, que había decorado las Salas del Palacio Pontificio en Roma, Vasari nos dice que "en sus pinturas usó muchos ornamentos de medio relieve de oro, para satisfacer a las personas que poco de aquel arte entendían... para que tuviesen mayor brillo y vida, lo que es cosa muy torpe en la pintura". ${ }^{13}$ Y en la vida de Cosimo Roselli, que había decorado una capilla del Palacio Pontificial de Sixto IV: "sintiéndose débil en invención y disegno, para ocultar sus defectos, usó finísimos azules ultramarinos y otros colores vivísimos, iluminando con oro toda la historia". ${ }^{14}$

Su repudio por el arte gótico y bizantino se basó en una nueva concepción teórica de la belleza. El concepto medieval de belleza como ornamentación añadida a la forma fue reemplazado por el concepto de la forma bella en sí, independientemente de su adorno. De ahí la reacción de Vasari contra el gótico vistoso y su repudio por los materiales agradables, por la

\footnotetext{
${ }_{12}$ Vasari, Giorgio, Le Vite..., Introduzione alle tre Arti del Disegno, 1, 129-30.

13 Ibid., Bernardino Pinturicchio, IV, 256.

it Ibidem., Cosimo Roselli, IV, 121.
} 
policromía y por los detalles decorativos. La inseparabilidad de la estructura y ornamento, uno de los aspectos fundamentales del gótico, sobre los cuales se funda la geometría como esencia de la estructura y de la ornamentación, no fue comprendida.

Este manejo peyorativo del gótico y del bizantino, a los que Vasari no reconoce ninguna aportación artística, no fue privativa de él, sino que revela los gustos y repulsiones del Cinquecento. Rafael, en su famosa carta a León X, sobre las condiciones de los monumentos y ruinas de la ciudad eterna, haciéndose portador de Castiglione y de Bramante, habla de las construcciones del "dominio de los godos", expresando que las encuentra tan carentes de gracia y de cualquier tipo de estilo, que no pueden ser consideradas ni antiguas ni modernas. Rafael relaciona lo que conocemos como arquitectura, comentando que cualquiera puede ver que su ornamentación está tan alejada de la buona maniera de los romanos y de los antiguos, que no puede ser considerada sino bárbara. Además de considerar que el arco apuntado es débil, encuentra que este tipo de arcos carece de gracia y que es la gracia la que place al ojo. Esta gracia sólo se encuentra en la perfección del círculo. ${ }^{15}$

Estas líneas nos revelan que la arquitectura gótica no fue del gusto de la época, sino un género aparte con sus reglas y preceptos peculiares. En cierta forma podemos decir que la tónica general del Cinquecento fue antimedieval.

Rechazado el arte gótico y el bizantino, la nueva edad comienza para Vasari hacia mediados del Trecento. En la vida de Giotto se refiere a la Edad Media como la "edad tosca e inepta", siendo todavía el siglo XIII "un siglo infeliz". Al principio de éste sólo se percibían algunos pocos signos de ese despertar que habría de cobrar fuerza hacia fines del siglo XIII; el progreso fue posible sólo después de una serie de cambios originados por los hombres de genio: estos precursores del arte nuevo fueron Cimabue, Giotto, Arnolfo di Cambio y Niccola Pisano.

15 Vogel, J., Bramante e Raffaello nei documenti nelle testimonianze dei contemporanei $e$ nella letteratura del suo secalo. Pontificio Accademia Artistica dei Virtuosi ai Pantheon, Cittá del Vaticano, 1936. 


\section{Primera edad}

La pintura fue para Vasari la primera de las artes que se emancipó de la "barbarie". Cimabue, si bien siguió el arte de los pintores griegos (bizantinos) llegados a Florencia, ayudó a la perfección del arte con su dibujo y su colorido, con el mejoramiento de la invención y el uso de una bella maniera en las actitudes. Es decir, Cimabue logró romper el convencionalismo pictórico bizantino: las actitudes hieráticas de las figuras, el uso de líneas y perfiles, orientándose hacia una pintura más viva y natural. Es importante destacar cómo todos los rasgos que emplea para rechazar el arte bizantino -morbidez, caída de los paños, belleza del disegno y del colorido-son propios del siglo XVI.

Niccola Pisano, superando en la escultura la vecchia maniera greca, tosca y desproporcionada de los bizantinos, dio a sus figuras una mejor actitud y una mejor invención. Sus conquistas en el dibujo fueron sin embargo parciales; a sus obras faltó un dibujo correcto y cierta facilidad.

Vasari admira Santa Ma. de las Flores y la Santa Croce, construidas por Arnolfo di Cambio, y a quien llama todavía "Arnolfo Tedesco", por la grandeza de su construcción y por su solidez, con lo cuaí marcó a quienes le siguieron la ruta de la perfección.

Giotto, ayudado por un don divino, es quien revela la verdad en la arquitectura, en la escultura y la pintura, extendiéndose su arte a todas partes de Italia. Giotto, al restaurar el naturalismo en la pintura, rompió definitivamente con el arte bizantino (o vecchia maniera greca). Vasari recoge las ideas ya apuntadas por Dante, Petrarca, Bocaccio, Villani, Cennini, Ghiberti y Landino, y en el Proemio a la segunda parte nos dice que Giotto dio a sus figuras mejores actitudes, mayor expresión a sus rostros, pliegues más naturales, realizó los primeros trazos en la perspectiva, cierta morbidez y expresión de sentimientos, conjunto de rasgos que se oponen enteramente a las características del arte bizantino. Aunque en la pintura de Giotto subsisten algunos rasgos de la pintura bizantina como el contorno de los ojos, de las barbas, el color azul y el color oro, Vasari considera que Giotto ha encontrado una nueva vía. 
En la arquitectura sin embargo, no reconoció a Giotto la misma importancia que en la pintura. Sólo señala que para el campanario de Santa Ma. de las Flores, concebido en maniera tedesca, Giotto dibujó los motivos ornamentales y distribuyó en el modelo los colores rojo, blanco y negro en todos los lugares en que iban las piedras y los frisos, con mucha habilidad.El campanario tuvo por base un cuadrado perfecto. Vasari atribuyó a la diligencia y minuciosidad de Giotto en la ornamentación del campanario, lo que en realidad es el principio constructivo del gótico: la geometría. Respecto a la escultura sólo nos dice que fue su dibujo el que marcó una nueva influencia en la escultura que habría de seguirle.

Vasari considera que aun cuando la arquitectura ha progresado, el orden, la regla, la simetría, no han alcanzado las exigencias del arte, ya que todavía los elementos son mezclados al azar, faltando invención y proporciones debidas.

Este renacimiento se continúa con Giovanni y Niccola Pisano, Ambrogio y Pietro Lorenzetti, Duccio, Andrea Pisano, Pietro Cavallini, Andrea Orcagna y Lorenzo di Bicci. Ellos ayudaron a liberar al arte de los convencionalismos de la época anterior. El vértice de esta maniera, es decir la perfección que ella podría alcanzar, fue lograda por Giotto, lo que lo coloca entre los mayores artistas de todos los tiempos, aun cuando desde el punto de vista de la técnica haya tenido sus limitaciones.

\section{Segunda edad}

En la escultura del Quattrocento, un primer grupo de artistas, encabezados por Iacopo della Quercia, se aproximan a una representación más exacta y flexible de la naturaleza. La escultura de Iacopo della Quercia marca una especie de transición, puesto que trató de aproximar su arte a la naturaleza imprimiendo a sus esculturas gracia y finura. En Lucca della Robbia Vasari admira el realismo y la gracia de sus formas, tanto como su fina ejecución. Ghiberti, junto con Donatello, será uno de los dos más grandes maestros del Quattrocento. Ghiberti aparece no sólo como el iniciador del pleno Renacimiento, sino 
como uno de los más grandes artistas de todos los tiempos. Vasari examina personalmente cada uno de los recuadros que forman las Puertas del Paraiso y destaca la extraordinaria imitación que en ellas hizo Ghiberti de la naturaleza, la originalidad y calidad técnica de los bajorrelieves, la perspectiva, la variedad de las figuras, la riqueza y la armonía de la composición.

Donatello, influido seguramente por las antigüedades que coleccionaba Cosimo de Medici, dio un impulso decisivo a la búsqueda de las mismas, restaurando incluso algunas estatuas antiguas. En Donatello, Vasari aprecia las innovaciones técnicas, la gracia de sus figuras, el realismo, gusta del peculiar acabado que Donatello dio a algunas de sus obras.

Los escultores que les siguen son considerados de menor importancia que Ghiberti y Donatello y sus estilos no están claramente definidos. Si bien sus esculturas se vieron influidas por éstos, permanecen ciertos defectos como la desproporción en la figura humana, la maniera que aún es seca, maniera que se manifiesta sobre todo en Pollaiolo y Verrochio.

En Verrochio admïra su universalidad: "orfebre, excelente en perspectiva, escultor, grabador y músico", en su escultura alaba la expresividad y belleza de las actitudes, la fisonomia de los personajes, la belleza moderna de los pliegues, pero le reprocha el haber tenido una maniera "un poco dura y seca". La característica que Vasari distingue para la escultura del Quattrocento es precisamente la sequedad.

En la arquitectura Brunelleschi es, según Vasari, el inventor del estilo del Renacimiento: "Y tanto más alabanza merece Brunelleschi, cuanto que en tiempos suyos la maniera tedesca era venerada en toda Italia y ejercitada por los viejos artífices... El recuperó las molduras antiguas y las órdenes toscano, corintio, dórico y jónico, en su forma originaria". Brunelleschi restauró así el arte antiguo pero en un estilo resueltamente moderno y florentino.

A Alberti Vasari le reprocha un exceso de dogmatismo: "Alberti se vio más inclinado a escribir que a actuar; le faltó la intuición y el dibujo, así como la práctica, que están más allá de la ciencia". Vasari considera que la arquitectura de Alberti es una arquitectura estricta, sin concesiones a la fantasía. 
Después de Alberti desfilan en la obra de Vasari algunos maestros cuyas obras son menos importantes, como Francesco di Giorgio, Bernardo Rosellino y Benedetto da Maiano, el último arquitecto del Quattrocento.

El análisis técnico de la arquitectura en este período permite seguir el esfuerzo por resolver los problemas constructivos. Si bien Vasari admira la solidez constructiva, rechaza la falta de fantasía en ese afán de adherirse a cánones estrictamente clasicistas.

Las referencias a la pintura son más abundantes. En ésta, los pintores se esfuerzan por romper los parámetros de la vieja escuela. Paolo Uccello a pesar de ser el gran innovador en la perspectiva y que Vasari le reprochaba el haber perdido tanto tiempo en ella, reconoce que la composición de sus dibujos geométricos es extremadamente complicada. Uccello, gracias al procedimiento lineal que utilizó para la representación espacial, fue el primero que superó la pintura de Giotto y sus seguidores, pasando del plano empírico al plano de la ciencia. Vasari considera sin embargo que su abuso por la perspectiva lo condujo a una pintura un tanto teórica.

Masolino da Panicale, de quien Vasari conoció pocas obras, es considerado como un innovador por la belleza que logró expresar en el cuerpo humano, por el empleo de una perspectiva superior a la de Giotto y sus seguidores y por haber empezado a utilizar luces y sombras, el esfumado y la armonía de los colores para lograr la perspectiva aérea. Considera además que sus figuras poseen morbidez y gracia.

Aparece entonces la figura de Masaccio, a quien proclama creador de la maniera moderna. Masaccio es para Vasari la síntesis de Uccello y Masolino. La superioridad de su dibujo le permitió representar los aspectos más difíciles de la realidad. Masaccio supo unir la perspectiva lineal de Uccello con la pintura aérea de Masolino. Masaccio fue el punto de partida de las bellas actitudes, de los "movimientos fieros y vivos".

Una larga lista de artistas sigue a Masaccio: Piero della Francesca quien destaca por la diversidad de sus expresiones, por la variedad de sus vestidos, por la maniera dolce e nuova; Fra Angelico; Antonello da Messina; Alessandro Baldovinetti, quien se esforzó por variar las técnicas pictóricas y quien tuvo 
una buona maniera de pintar al fresco; Filippo Lippi, en quien aprecia la calidad del dibujo, la caída de los paños, la expresión de los rostros, la expresión de sentimientos: "Filippo representó en su pintura las más grandes figuras de la realidad, y es por esto que introdujo entre los modernos la grandeza del estilo que ahora vemos". La pintura de Andrea del Castagno fue vigorosa, aunque violenta y sin gran finura; su dibujo fue duro y su color demasiado dulce. Le siguen Domenico Veneziano; Gentile Ghirlandaio, uno de los más excelentes maestros de su época y en quien se manifiesta el progreso del disegno, es visto por Vasari como uno de los precursores de la gran maniera moderna. En Perugino aprecia la originalidad de la maniera personal. Así, luego de un desfile interminable de artistas, aparece la figura de Lucca Signorelli, en quien siente que convergen las tendencias del Quattrocento. Es como un precursor de Miguel Angel, "al introducir la maniera de hacer los desnudos"; estableció los fundamentos del dibujo, es decir, la gran maniera. Su talento se manifestó en su invención, en su habilidad técnica, en su fantasía creadora: "Lucca representó las historias del fin del mundo con una bizarra y caprichosa invención; puso en escena los ángeles, los demonios, los temblores de tierra, el fuego, el Anticristo y muchas otras cosas semejantes..." Sin embargo, una maniera todavía seca - dice- priva en el dibujo de Signorelli.

Todas las aportaciones del Quattrocento son la vía de acceso al Cinquecento, lo que le permite trazar la continuidad en el arte y la superioridad de su propia época.

\section{Tercera edad}

No obstante que la arquitectura se inicia con el brillo de Bramante, los datos que Le Vite aporta acerca de sus primeros años son escasos; a Bramante lo encontramos ya en Roma, al servicio de Julio II, hacia los cincuenta años de edad, dedicado a estudiar en forma exhaustiva las ruinas romanas. De las pocas obras que señala no nos da sino detalles estructurales y ornamentales, y lo mismo sucede con la reconstrucción de San Pedro, en la que admira la belleza del orden dórico que refleja el espíritu extraordinario de Bramante. Al no mencionar ningún 
dato que revelara aspectos interesantes sobre sus construcciones, no es posible percibir las influencias que Bramante recibió y cómo las proyectó.

Giuliano da San Gallo dio al orden dórico mejor medida y proporción que la que había logrado la tradición de Vitrubio; Giuliano y Antonio da San Gallo, al lograr ellos mejores formas que las que privaron anteriormente, dieron al arte las maniere de la arquitectura toscana. Simone dal Pollaiolo, llamado El Cronaca, aparece como uno de los arquitectos de transición; aprecia el Palacio Strozzi en el que el Cronaca superpuso acertadamente los órdenes arquitectónicos. Antonio da San Gallo el joven supo combinar en sus construcciones militares la gracia y el ritmo con la severidad de las fortificaciones. Vasari destaca en San Gallo el joven a un constructor moderno que supo dar comodidad a sus construcciones. Entre otros arquitectos más, aparece la figura de Giulio Romano, renovador de la maniera graziosa. Los elementos clásicos son empleados por él con las más bellas proporciones, en "una nueva y extravagante maniera"; aprecia. la movilidad de las formas que empleó en la construcción de su propia casa. Antes de llegar a Miguel Angel desfilan en Le Vite Niccolo de Tribolo; Baccio Bandinelli; Giuliano d'Agnolo; Bramantino; Michele San Michele, a quien podríamos declarar un romanista por su apego a los cánones de la arquitectura clásica; Girolamo Genga, quien supo conjugar la proporción, la gracia y la composición con la arquitectura clásica, logrando una maniera que podríamos considerar universal.

Después de otras biografias, Vasari pasa a la biografía de Miguel Angel, considerado como el apogeo del Renacimiento. En la Sacristía de San Lorenzo Vasari se percata de que los órdenes clásicos han sido notablemente modificados y las proporciones son un tanto insólitas. La liberación de los cánones clásicos anunciada en la Sacristía es reafirmada en la Biblioteca de San Lorenzo, en la que Vasari aprecia el bello orden de las ventanas, el disegno del plafón, el vestíbulo y la escalera; en el Palacio Senatorial la novedad está puesta en la doble rampa de la escalera; los otros dos palacios de la misma plaza poseen una fachada rica y variada y una logia llena de columnas y de nichos. San Pedro fue construida "con majestad y grandeza de 
órdenes, de disegno, de belleza y de comodidad'. Las últimas obras arquitectónicas de Miguel Angel parecen culminar en una liberación de la arquitectura; las fachadas son variadas, ornamentadas, con nuevos órdenes, extravagantes y bellas. Vasari comprendió claramente uno de los cambios principales de su tiempo: el hecho de que Miguel Angel podía violar las normas estrictas de la arquitectura para jugar con las formas, combinándolas armónicamente. En Miguel Angel había culminado la liberación de formas y ritmos para dar paso, a través de lo que hoy denominamos manierismo, a un nuevo movimiento artístico: el barroco. Con Miguel Angel había nacido la verdadera maniera en la arquitectura.

Después de la biografia de Miguel Angel, Vasari nos transporta a Venecia, con la biografía de Iacopo Sansovino, quien a diferencia de los que levantaron monumentos antes que él, construyendo sólo en un orden y siguiendo las viejas medidas sin aportar ninguna variación, comenzó a construir con un nuevo dibujo y un mejor orden. Las biografías que le siguen se refieren a aquellos que aún vivian y que pertenecían a la Accademia del Disegno.

La escultura del Cinquecento recibió de Leonardo da Vinci un impulso decisivo. El primer gran escultor es Andrea dal Monte Sansovino, al emplear en su escultura las medidas antiguas y modernas. Su escultura, que tiende a lo monumental, se caracteriza por su vivacidad, su naturalidad, su movimiento, la graciosa caída de los paños, su finura y riqueza de invención. Benedetto da Rovezzano es apreciado por el virtuosismo de sus obras, por la exquisitez de sus trabajos, además de la riqueza ornamental y la redondez de sus figuras.

Después de otros artífices excelentes, Vasari aprecia las obras de Agnolo Montorsoli, en las que hay una perfección formal que revela las tendencias de la época: la escultura se complica y rivaliza en las formas con la pintura; hay un lujo decorativo; las figuras tienden a la monumentalidad y al gigantismo; la riqueza de sus composiciones provoca cierta confusión en las figuras.

Aparece entonces el genio de Miguel Angel, cuyas esculturas de los primeros años poseen una perfección formal muy similar a la de los antiguos, unida a una gracia que acompañará 
siempre las esculturas del maestro. En ellas se conjugan el naturalismo y la belleza: las medidas perfectas, la delicadeza de los detalles, la robustez de las formas. Entre los trabajos del período de madurez se encuentran las Tumbas de los Medici, que por su belleza y su magnificencia superaron a las esculturas de los antiguos. Cuando Vasari describe las últimas obras, recurre a la imaginación tormentosa del viejo Miguel Angel, incapaz de adherirse a formas naturales o a algún modelo en especial. Miguel Angel precipita su turbulento pensamiento sobre el mármol, y alejado de la vanidad de este mundo, se vuelca hacia la divinidad. Vasari nos dice que tan grande y perfecta era su imaginación que cuando no podía expresar sus conceptos con las manos, abandonaba sus esculturas y comenzaba a tallar un nuevo mármol.

Después de Miguel Angel, Iacopo Sansovino representa la novedad de todo aquello que Miguel Angel no pudo expresar en sus obras: en su escultura se funden la delicadeza, la finura de los detalles, la plasticidad del modelado, la belleza de las actitudes y las proporciones, así como los movimientos graciosos. Después de las vidas de Miguel Angel y Sansovino, Vasari continua con una larga lista de escultores como Ammanati, Cellini y Giambologna.

Por lo que respecta a la pintura, Leonardo da Vinci, Giorgione y Correggio son los creadores de la maniera moderna.

En la pintura de Leonardo se reconoce la diligencia, la expresividad, el esfumado del color. Ante Giorgione, Vasari se encuentra con el problema de no poseer suficiente información, además de que confiesa que conoce mal sus obras. Aun así, considera que su papel en Venecia es tan importante como el de Leonardo en Florencia. No pudiendo explicarlo, admira sin embargo la vivacidad de su colorido. Correggio cierra la trilogía de innovadores "al haber iniciado en Lombardía la maniera moderna". La perfección de sus obras se fundó en su dibujo, en su práctica, en la morbidez lograda por el tipo de pinceladas que utilizó: Correggio supo expresar en el arte, con gracia y facilidad, los detalles difíciles de la naturaleza.

Después de estos innovadores desfilan Piero di Cosimo, ante quien Vasari se muestra un poco desconcertado y en quien aprecia sus composiciones bizarras y las formas extrañas 
producidas por su fantasía; Fra Bartolomeo di San Marco y Mariotto Albertinelli, en cuyas obras se registra el esfumado de Leonardo. Después de otros pintores llegamos a la vida de Rafael, en quien sigue la evolución de sus maniere. Su primera etapa está ligada a las obras de Perugino; luego ésta es superada en el dibujo, el colorido y la invención, hasta alcanzar una maniera universal que se expresa en un disegno terribile, una invención copiosa y variada y un color agradable.

Después de Rafael se encuentran algunos pintores que podríamos considerar en segundo término, hasta encontrarnos con las vidas de Polidoro da Caravaggio y Maturino, en quienes Vasari encuentra las principales cualidades académicas: abundancia y claridad en las composiciones, dibujo correcto, maniera universal, invenciones clásicas y alegóricas. Rosso Fiorentino, cuyo arte Vasari comprende mal, reduciéndose a comentar su dibujo académico: dotado de una maniera graziosa, su dibujo fue "fiero y bien fundado"; en sus obras se muestra un gran realismo en las representaciones, en la expresión de sentimientos; como nota distintiva señala que "no pudo permanecer en ningún taller por haber tenido una cierta concepción de la pintura opuesta a la de los demás".

En Parmigianino destaca las tendencias eclécticas que se fundieron en un estilo personal. Vasari trata de analizarlo para descubrir aquello en lo cual consiste ese carácter personal de su obra, pero no lo logra, y nos da sólo descripciones al estilo de la ekphrasis. En Pontormo trata de rastrear sus influencias, sus maniere; sin alcanzar una explicación que a él mismo satisfaga, percibe con claridad las alteraciones de su buona maniera moderna: la dulzura y la gracia, la expresividad de los rostros, las extravagancias, las invenciones, el uso del color, las innovaciones.

Una lista interminable de pintores nos lleva hasta Francesco Salviati, que personifica el ideal de la generación que sucedió a Miguel Angel y Rafael. Su aprendizaje en Florencia y Roma le permitió alcanzar una maniera universal. En su excelente dibujo se multiplican los desnudos y los escorzos; su composición es correcta, agradable, hábil; el movimiento expresivo, el virtuosismo de la imitación y las invenciones son admirables. En Salviati percibe asimismo su talento decorativo 
y la introducción de motivos arqueológicos, simbólicos y alegóricos.

A Federico Zuccari, Vasari le concede gran importancia. Es uno de los académicos del/disegno que más tarde habría de dirigir la Academia de San Lucas de Roma. Su dibujo se deriva de Miguel Angel; en sus obras hay algunos toques secos debidos a un exceso teórico; sus colores son agradables y graduados y las expresiones variadas.

Después de Zuccari aparece Miguel Angel, en quien Vasari se preocupa por seguir las huellas de los maestros que lo influyeron. Cuando llega a los frescos de la Capilla Sixtina, más que preocuparse por su significación religiosa, Vasari centra su atención en las figuras, en las anatomías, en las perspectivas, en los gestos y en los sentimientos. Su análisis sobre el Juicio Final es breve, un tanto impersonal y vago. No obstante la importancia de Miguel Angel, la descripción que Vasari hace de sus obras es superficial, destacando en ellas más bien aspectos de carácter técnico.

\section{Acerca del arte clásico romano}

El hecho de que el arte clásico (romano) se constituyera en la fuente de conocimientos y de inspiración, estimuló el estudio de los monumentos antiguos. Roma había estado siempre presente en el medioevo italiano y el románico pretendía ser una continuación directa de la cultura romana. Sin embargo, la admiración por Roma como ideal estético supremo en el Renacimiento significaba la conciencia de una ruptura con el pasado reciente y de una declinación de sus valores. Como consecuencia, Roma se constituyó en un centro de peregrinaje de artistas que admiraban el arte antiguo. La práctica de visitar Roma con propósitos de estudio y de exploración metódica de las ruinas antiguas empezó a asumir el riguroso aspecto de un sistema. Este estudio fue acompañado de innumerables producciones gráficas. Los artistas examinaban las proporciones, las decoraciones, las formas estilísticas, tendiendo a un descubrimiento de las leyes estructurales fundamentales. A mediados del siglo 
$\mathrm{XV}$, Roma, el centro más rico en la tradición antigua, se adhería más que ninguna otra ciudad a los ideales clásicos.

Vasari, ilustre viajero y gran admirador de la belleza romana, "estimulado por el afán de alcanzar la gloria ...se propuso dibujar cuanto de notable había en Roma y Florencia". A través de Le Vite encontramos innumerables noticias sobre la profunda veneración que se tuvo por el arte romano:

Lorenzo Ghiberti fue el primero que comenzó a imitar las cosas de los antiguos romanos, de las cuales fue muy estudioso, como deben ser todos aquellos que deseen trabajar bien. ${ }^{16} \mathrm{Ma}-$ saccio, no sintiéndose en Florencia a gusto y estimulado por el afecto y amor al arte decidió irse a Roma para aprender y superar a los otros. ${ }^{17}$ Después del concurso para la ejecución de las puertas de bronce de San Juan, que fue ganado por Ghiberti, Donatello y Brunelleschi, que habian participado en él, decidieron salir de Florencia para dirigirse a Roma: Donatello para estudiar escultura y Brunelleschi arquitectura, que consideraba de más utilidad para los hombres. Brunelleschi, al llegar a Roma, viendo la grandeza de los edificios y la perfección de las estructuras de los templos, estaba tan abstraído que parecía fuera de sí. El único objetivo de Brunelleschi era la arquitectura ya extinguida, es decir, los buenos órdenes antiguos y no la bárbara y tedesca. ${ }^{18}$ Peruzzi Baldasarre empezó a escribir un libro sobre las antigüedades de Roma y a comentar a Vitrubio. ${ }^{19}$ Para conocer la antigüedad de aquellas maravillosas reliquias que son el verdadero maestro, Fra Giocondo resolvió visitar Roma, donde permaneció doce años, tiempo que en su mayor parte dedicó a ver y dibujar toda aquella maravillosa antigüedad, cavando tanto en cada lugar hasta que pudiese ver las plantas y reencontrar todas las medidas. No dejó cosa en Roma o de construcción o de sus miembros, como son cornisas, columnas y capiteles de cualquier orden, que no dibujara con todas sus medidas. Copió también todas las esculturas que fueron descubiertas en aquellos tiempos, de manera que des-

\footnotetext{
16 Vasari, G., Le Vite..., Lorenzo Ghiberti, III, 83.

17 Ibid., Filippo Brunelleschi, III. 139.

18 Ibidem., Masaccio, III, 120.

19 Ibidem., Baldasarre Peruzzi, VI, 115.
} 
pués de aquellos doce años regresó a su patria riquísimo de todos los tesoros de este arte. ${ }^{20}$

El estudio de las ruinas romanas se constituyó en una condición esencial al arte del Quattrocento. Todavía cuando Vasari se acerca al arte veneciano, considera que Giorgione y otros que jamás fueron a Roma "no podrán alcanzar en el arte la última perfección".

Sin embargo, Vasari, al desprenderse de los cánones "romanistas", fue uno de los primeros escritores que advirtieron que la civilización moderna no consistía en una resurrección del pasado glorioso, sino en una civilización con características propias y definidas. La perfección descubierta en los principios de la arquitectura romana fueron sólo el punto de partida.

El renacimiento artístico exigió el desarrollo de nuevas ideas, de innovaciones formales y la necesidad de formular principios y reglas propias, para lo cual el arte clásico se convirtió, no propiamente en un prototipo formal, sino más bien en una rica fuente de conocimientos e inspiración.

El estudio directo de los monumentos àntiguos -romanos- constituyó el fundamento del clasicismo arquitectónico del Renacimiento. Los elementos de la arquitectura romana fueron estudiados y valorados para luego ser fundidos en una nueva concepción del espacio y del mundo.

En la escultura, la forma no fue una simple imitación de los modelos clásicos. La realidad se expresó en una nueva forma artística, impregnada de un nuevo significado humanístico. Antigüedad y naturaleza se fundieron en nuevas formas escultóricas.

El renacimiento de la pintura, por otra parte, no consistió en poner los ojos en la antigüedad, sino en rescatar algo que había permitido a ésta el esplendor de las artes plásticas: el retorno a la imitación de la naturaleza, entendida ésta no como una reproducción exacta de la realidad natural, sino más bien como uno de los principios creativos del arte; las formas orgánicas, vitales, sustituyeron la inmovilidad, la frontalidad y el espacio convencional propios de la pintura gótica y bizantina.

De esta manera, la antigüedad clásica proporcionó las ba-

${ }^{20}$ Ibidem., Fra Jocondo, VII, 83. 
ses para la creación artística. El principio de imitación de la naturaleza y el principio de selectividad de las más bellas partes lograron la conformación del ideal clásico, que en tiempos de Vasari no sólo había alcanzado su más alta expresión, sino que precisamente en virtud de la perfección alcanzada, se había iniciado un complicado proceso que implicó la aceptación de una tendencia anti-clásica.

Vasari siempre enfatizó el valor de lo clásico en tanto que este término implica un principio de selectividad en el orden natural, sin embargo fue consciente en su momento de que el idealismo clásico, tal y como había sido entendido por los humanistas, implicaba la superación tanto de los modelos tomados de la naturaleza, como de aquellos que derivan de la imitación del arte antiguo. 